\begin{tabular}{|c|c|}
\hline Title & Effects of colour narrative in community-dwelling older adults: A mixed methods study \\
\hline Author(s) & Takashima, Risa; Inoue, Takao; Y oshida, Y uko; Sakaue, Mari; Suzuki, Teppei; Ogasawara, Katsuhiko \\
\hline Citation & $\begin{array}{l}\text { Scandinavian Journal of Occupational Therapy, 29(7), 542-554 } \\
\text { https://doi.org/10.1080/11038128.2020.1849395 }\end{array}$ \\
\hline Issue Date & 2020-12-05 \\
\hline Doc URL & http:/hdl. handle.net/2115/83425 \\
\hline Rights & $\begin{array}{l}\text { This is an A ccepted Manuscript of an article published by Taylor \& Francis in Scandinavian Journal of Occupational } \\
\text { Therapy on 05 Dec 2020, avail able online: http:/www.tandfonline.com/10.1080/11038128.2020.1849395 }\end{array}$ \\
\hline Type & article (author version) \\
\hline File Information & manuscript - 修正版.pdf \\
\hline
\end{tabular}

Instructions for use 


\section{Effects of Colour Narrative in community-dwelling older adults: a mixed methods study}

Risa Takashima ${ }^{a}$, Takao Inoue ${ }^{a^{*}}$, Yuko Yoshida ${ }^{a}$, Mari Sakaue ${ }^{b}$, Teppei

Suzuki $^{\mathrm{c}}$, Katsuhiko Ogasawara ${ }^{\mathrm{a}}$

${ }^{a}$ Faculty of Health Sciences, Hokkaido University, Sapporo, Hokkaido,

${ }^{b}$ School of Health Sciences, Sapporo Medical University, Sapporo, Hokkaido, Japan

${ }^{c}$ Hokkaido University of Education, Iwamizawa Campus, Iwamizawa, Hokkaido, Japan

*Corresponding author

Name: Takao Inoue (Dr.)

Address: N12-W5, Kitaku, Sapporo 060-0812, Japan

E-mail: ot-inoue@huhp.hokudai.ac.jp

Tel: $+81-(0) 11-706-3380$

Running headline: Effects of Colour Narrative in Older Adults 


\begin{abstract}
Background: Based on occupational storytelling/story-making, this study developed Colour Narrative, a program to promote the health and wellbeing of community-dwelling older adults. Objectives: To conduct a pilot study to implement Colour Narrative in a heavy snowfall area of Japan and verify the participants' experiences in the program and its effectiveness. Material and Methods: An advanced mixed methods design was used. The participants were 22 members of a community-based social group for older adults. Quantitative measurements of life functions and health-related quality of life (HRQOL) were conducted before and after the intervention. Qualitative data were collected from focus group interviews regarding the participants' experiences during the intervention process. Lastly, both datasets were integrated. Results: The harsh living conditions due to heavy snowfall reduced the participants' overall activity. In this environment, Colour Narrative encouraged them to control their lives more in their own ways and enhanced their HRQOL. The core of their experiences was 'negotiating occupations'. This negotiation was a highly intellectual task that significantly improved their cognitive function. Conclusions: The structure and content of Colour Narrative were found to be useful and feasible for community-dwelling older adults. Significance: Colour Narrative offers a new occupation-based intervention strategy for preventive occupational therapy.
\end{abstract}

Keywords: Storytelling, story-making, narrative, older adults, community, preventive occupational therapy, snow country, mixed methods study 


\section{Introduction}

Florence Clark introduced the use of therapeutic stories in the context of occupational therapy [1]. Clark helped Penelope L. Richardson, a stroke survivor, to rebuild her own life by extracting stories from her. Clark referred to the approach as occupational storytelling (ST)/story-making (SM) [2]. A study using ST/SM as an intervention protocol reported that women with multiple sclerosis understood the meaning of and developed an occupational strategy to cope with the invasiveness of their disease [3]. Gunnarsson et al. [4,5] introduced the 'Tree Theme Method', an intervention based on a creative activity and life ST/SM. The researchers reported that performing life ST/SM by drawing trees to represent different periods in their lives helped awaken the participants' memories and feelings; generated new perspectives on self-image, everyday life, and relationships with others; and helped shape and reconstruct their life stories.

Although ST/SM are proven to be useful intervention protocols, they have only been applied to clients with a specific disease or disorder. Occupational therapy clients also include people who have or expect to have difficulties with daily occupations $[6,7]$. With virtually every country worldwide experiencing an aging population [8], community-dwelling older adults could make a large portion of occupational therapy clients. In the Well Elderly Study, which implemented Lifestyle Redesign as a pioneering intervention based on occupations for community-dwelling older adults in the USA, the experimental group showed significantly better health-related quality of life (HRQOL) [9,10], life satisfaction $[9,10]$, and scores on the quality of interaction scale of the Functional Status Questionnaire [9]. Further, this intervention showed a higher cost-effectiveness [10] than the methods used in control groups (social activity program and/or no treatment), and maintained approximately $90 \%$ of its therapeutic 
effects in the six-month follow-up conducted post-intervention [11]. Regarding depressive symptoms, one study showed better outcomes in the experimental group [10], while another showed no significant differences [9]. Balance, cognitive function, basic/instrumental activities of daily living (IADL), and social activities were not significantly different between the two groups [10].

In contrast, Yokoi, Fujii, and Sakai [12] reported significant improvements in cognitive function through a program in which participants selected and performed challenging occupations. Furthermore, in a study using a program based on the model of human occupation, the experimental group had significantly higher HRQOL than the control group (handicrafts) [13]. Additionally, in a study using LifeMatters, an occupation-based approach to improving well-being and preventing social isolation, the experimental group had higher HRQOL than the control group (usual care), although the difference was not significant [14]. Thus, it has been frequently reported that occupation-based preventive interventions can improve participants' HRQOL. However, reports of the effects of these interventions on participants' functional health have mostly been limited. Specifically, no effects have been reported on balance function, IADL, or social activities, and research results have been inconsistent with respect to mental and cognitive function.

Therefore, we developed Colour Narrative, a preventive intervention program based on occupational ST/SM, to improve the HRQOL and functional health of community-dwelling older adults. This approach can provide an opportunity for older adults to think about how they want to design their lives, while the process of occupational SM allows them to experience actually designing their own lives. This study aims to conduct a pilot program to examine whether Colour Narrative can contribute to the promotion of HRQOL and functional health in occupational therapy 
clients without specific diseases or disabilities, such as community-dwelling older adults. If this intervention is found to be effective in this population, it is expected to provide a new occupation-based strategy for occupational therapists active in health promotion.

\section{Theoretical framework}

Clark et al. [2] describe the approach based on occupational ST/SM in three steps: 1) building 'a communal horizon of understanding', 2) occupational ST, and 3) occupational SM. In the first step, therapists try to adopt a neutral position as a layperson instead of a professional. This represents a fusion of both the therapist's and client's perspectives (horizon of understanding). Second, in occupational ST, the stories regarding the clients' occupations are generated, analyzed, and integrated. Therapists understand the importance of the meaning given by the client to a particular occupation and use it in the next step, occupational SM. Finally, occupational SM builds a story of a future where the clients can immerse themselves in their occupations. The aim is for the client to continue living as an occupational being. Clark [1] argued that occupational ST/SM should be at the core of the clinical reasoning of the occupational therapist to nurture the human spirit to act.

The present study used colour cards as visual mediators in occupational ST. Common forms of participatory visual methodologies include photo, voice, and digital ST [15]. Using visual mediators in ST has been reported to increase participants' positive emotions during the recruitment and research processes, which promotes communication and concentration during an interview [16]. In addition, by telling a story after choosing a colour card, participants could avoid over-simplification of their experience. 


\section{Materials and methods}

\section{Research design}

This pilot study used an advanced mixed methods design to verify the effects of Colour Narrative, a program developed for community-dwelling older adults based on occupational ST/SM. We quantitatively examined the effects of Colour Narrative on the HRQOL and functional health of participants in a heavy snowfall area, and adopted a convergent design to qualitatively review the intervention process, in order to examine how participants experienced the program and its implications. The quantitative and qualitative data were analyzed separately, then combined. While quantitative results typically reveal general trends and relationships, qualitative results provide deep, personal perspective on the participants [17]. This design provides a more complete understanding of the target phenomenon than would be possible by using only a single dataset [17].

\section{Participants}

We asked A city, a heavy snowfall area in Japan that has a partnership agreement with our affiliation, to introduce the researchers to 'salons' interested in participating in this research. Salons are community-based centres that have recently been recommended as a health promotion strategy for community-dwelling older adults in Japan [18]. Older adults can engage in various social activities in salons.

Public health nurses introduced the researchers to B salon. About 25-30 people gathered at B salon once a month between 10:00-15:00. B salon does not charge a participation fee. Instead, the participants were asked to bring one cup of rice to every other salon session. The members can choose from various activities, such as cooking, handicrafts, card games, sudoku, mah-jong, group activities, and gymnastics. 
Study participants were recruited at B salon. A total of 22 members (3 men and 19 women, with a mean age of $76.1 \pm 5.8$ years) wanted to participate. To respect the culture of this salon, there were no criteria for exclusion according to participant physical or cognitive function, and all applicants were included in this study. Two of the them used long-term care services. Of the participants, 21 lived within walking distance of the salon, while one drove there in her own car. The 22 participants were divided into four groups of five or six, considering the timing of their chosen salon activities. All participants who agreed to participate in the study also expressed their desire to participate in Colour Narrative. Therefore, to ensure that all participants could be included, this study did not include a control group.

\section{Intervention program: Colour Narrative}

Colour Narrative includes five phases (Fig. 1).

[Insert Fig. 1 Here]

\section{Phase 1: Building a communal horizon of understanding}

The first author, an intervener, participated in the salon three times only as a member. The first author brought the participation fee of a cup of rice, like the other members, and participated in their activities.

\section{Phase 2: Colour-mediated occupational ST and setting occupational goals}

The four participant groups underwent occupational ST using colour cards as a visual medium for nearly 90 minutes per group. The groups were staggered, and the first author acted as the facilitator for all groups.

A game called 'Iro Karuta', which means colour card game in Japanese, was previously developed to provide colour care for people with dementia [19]. In the 
present study, colour cards consisting of 128 colours were used. First, to familiarize the participants with the colour cards, the facilitator asked the participants two questions from 'Iro Karuta': 'What is a sweet colour?' and 'What colour is your favourite season?' Thereafter, two unique questions were asked to perform occupational ST: 'What time of your life would you say you are/were the brightest? What are/were you doing at that time?' and 'While doing that, what do you feel/when have you felt most like yourself?' For each question, the participants chose a colour card that symbolized their experiences. They then explained why they chose the colour and the experiences they had recollected.

Then, during the next 30 minutes, participants used a worksheet to set occupational goals to improve their lives over the next three winter months. The worksheet consisted of five steps. First, based on the content of the occupational ST, the participants listed the occupations they would like to continue or restart, or the new challenges they would like to take on. Second, they selected one or more of the listed occupations that they would like to work on in the next three months and wrote down the reasons. Third, the selected occupations were described as concretely as possible, including the particular occupational forms. Fourth, issues that might arise when implementing their plans and countermeasures were described. Finally, they were asked whether they believed they could achieve their goals, to which they responded with either 'Yes' or 'No'. While the worksheets were collected for analysis by the researchers, the participants made copies to keep of their written goals.

The goals and features of the goals described by the participants are shown in Table 1. The researchers determined the features of the goals based on what the participants wrote in the first step of the worksheet. However, based on their responses, 
the occupations they wanted to pursue further were divided into 'occupations they want to continue' and 'occupations they want to improve'.

[Insert Table 1 Here]

\section{Phase 3: Occupational SM}

Each participant worked toward their planned goals for three months during winter (two groups from October 2018 to January 2019, and the other two groups from November 2018 to February 2019).

Phase 4: Reflecting on Phase 3 and updating goals

After their three-month period, participants were divided into the same groups as in Phase 2. Each group reflected on the previous three months for about 90 minutes. The first author acted as the facilitator for all groups. Table 1 shows whether the targeted occupations were performed, whether the occupational goals were achieved, and the participants' occupational performance statuses. Participants' actual occupational performance in Phase 3 and their updated goals at Phase 4 are presented in Supplemental File 1.

[Insert Supplemental File 1 Here]

Finally, participants updated their goals to improve their lives for the remaining time until March, which marks the end of winter. The updated goals that participants entered at the time are shown in Table 1.

\section{Phase 5: Further occupational SM}

The updated goals were implemented independently for the remaining one or two months of the winter. 


\section{Data collection}

\section{Quantitative data collection}

As noted above, improvements in HRQOL have been reported in occupation-based preventive interventions. In contrast, the reported effects on functional health in the current literature have been very limited, and the results on mental and cognitive function have been inconsistent. Therefore, in this study, quantitative outcome measures were selected based on the International Classification of Functioning, Disability and Health [20], to measure the functional health of participants in addition to HRQOL. The measures included demographics (age, gender, and family structure), mental function (cognitive function and depressive symptoms), activity (exercise habits and IADL), participation (engaging in valuable occupations), and HRQOL. Measurements were taken in August 2018, before Phase 2 of the intervention, and in March 2019, after Phase 5.

Three assessments were used to measure cognitive function. First, Part A of the Trail Making Test (TMT-A) was used. The TMT is a widely used neuropsychological measurement of psychomotor speed, attention, order, mental flexibility, and visual scan testing $[21,22]$. To reduce the burden on the participants, only Part A was used. Second, the standard verbal paired-associate learning test (S-PA) [23] was used. The S-PA measures verbal memory performance, and comprises related and unrelated pairedwords tests. Third, the Japanese version of the Mini-Mental State Examination (MMSEJ) [24] was used. The MMSE is a dementia screening test that is widely used worldwide [25]. On a scale of 1 to 30 , a score of 23 or less is considered to indicate dementia, and a score of 24-27 is considered to indicate mild cognitive impairment (MCI) [24].

To measure depressive symptoms, the Japanese version of the Geriatric Depression Scale-15 (GDS-15-J) [26] was used. The GDS-15 is the most commonly 
used depression screening test for older adults worldwide, and has both high validity and reliability [27]. On a scale of 1 to 15 , a score of 7 or higher indicates presumptive depression.

Information about exercise habits was collected on the following five levels, based on the Transtheoretical Model (TTM) to explain behaviour changes [28,29]: Precontemplation, Contemplation, Preparation, Action, Maintenance.

To measure HRQOL, the World Health Organization Quality of Life 26 (WHOQOL-BREF) [30] was used. WHOQOL-BREF measures participants' subjective well-being and QOL. Of its 26 items, 24 measure the QOL of physical, psychological, social relations, and environmental domains, and 2 measure overall QOL. For each item, responses are provided on five-point Likert scales.

To measure IADL, we used the Japanese version of Frenchay Activities Index (FAI-J) [31]. Its validity has been tested among community-dwelling older adults in Japan [32]. The scale comprises 15 items to evaluate IADL: preparing main meals, washing up after meals, washing clothes, light housework, heavy housework, local shopping, social occasions, walking outside, actively pursuing hobbies, using transportation, travel outings, gardening, household maintenance, reading books, and gainful work. The activity frequency in the last three months is evaluated with scores ranging from 0 to 3 . The sum of the scores is expressed as a scale, ranging from 0 (inactive) to 45 (active).

Finally, the Self-completed Occupational Performance Index (SOPI) [33] was used to measure the participation status of valuable occupations. Based on the Canadian model of occupational performance and engagement, the SOPI was designed to measure the quality of participation in activities of daily living. The SOPI consists of nine items, including 'occupational control', 'occupational balance', and 'satisfaction of 
performance', in the following three domains: leisure activity, productive activity, and self-care. Each of the nine items is scored on five-point scales ranging from ' $1=$ hardly satisfied' to ' 5 = very satisfied'. The SOPI score is calculated by converting raw scores into $0-100$ (100 score conversion formula: (raw score -9$) \div 36 \times 100)$. The higher the score, the more satisfied the individual is in performing a valuable occupation.

\section{Qualitative data collection}

At Phase 4 of the intervention, participants reflected on their experiences during Phase 3. A focus group interview was conducted for about 90 minutes per group. The first author, who was the only interviewer, is an occupational therapist with a $\mathrm{PhD}$ who has work experience in the field of health care involving older adults. To encourage participants to reflect, the following interview guide was prepared: 'Could you please tell me in as much detail as possible about how you put your goals into practice?' and 'If not, what do you think was the reason or cause for not completing your goal?' The interviews were conducted in Japanese, recorded, and transcribed verbatim.

\section{Data analysis}

\section{Analyses of the quantitative data}

First, descriptive statistics were calculated for all the obtained data. For each variable before and after the intervention, TMT-A, SP-A, and MMSE-J scores were analyzed using the paired $t$-test, and GDS-15-J, WHOQOL-BREF, FAI-J, and SOPI scores were analyzed using the Wilcoxon signed-rank test. For the WHOQOL-BREF, FAI-J, and SOPI, in addition to the total score, the subitem scores were also analyzed. Statistical analysis was performed using SPSS version 22.0 (IBM Corp., Armonk, NY, USA) at a significance level of less than $5 \%$. 
As for effect size, $r$ was calculated, which is recommended to be used for intuitive understanding, because the magnitude of the effect falls within the range of $0-1$ [34]. Here, $r \geqq .10$ indicates a small effect, $r \geqq .30$ or more indicates a medium effect, and $r \geqq .50$ indicates a large effect [34]

\section{Analyses of the qualitative data}

The grounded theory approach of Corbin and Strauss [35] can be used not only for theorizing but also to describe and organize concepts according to research objectives. To describe how participants experienced the occupational SM in phase 3, the grounded theory approach was applied to the analysis. The first author reviewed the transcribed interview data carefully, divided the data using natural changes in ideas while speaking as cut-off points, and coded all data. Based on properties and dimensions, coded concepts were compared, and related concepts were categorized into higher-level concepts. Finally, the core category [35] was explored and integrated to link each category.

To increase the trustworthiness and credibility of the data analysis [36,37], the researchers first attended the participants' salon once a month for one year and spent time with them. A continuous comparative analysis was performed and described in detail following the analysis process. Then, three co-researchers with experience in qualitative research repeatedly examined the data until consensus was reached. The qualitative data analysis results were shared with three research participants who mainly ran the salon, and member checking was performed.

\section{Merging the data}

Quantitative and qualitative data were collected and analyzed separately; however, both 
datasets were merged at the end of the analysis. Merging is a type of integration in mixed methods research that is frequently used for convergent study designs [17]. Merging compares the results of quantitative and qualitative data to determine whether they converge or diverge. In this study, quantitative and qualitative data were structured and compared using a side-by side joint display, which Creswell [17] recommends be used for merging. The merging results were discussed among the co-researchers and revised until consensus was reached.

\section{Ethics}

The study protocol was approved by the research ethics committee at the authors' affiliated institution (approval number: 18-36-2). The participants were provided verbal and written explanations regarding the guarantee of anonymity, confidentiality of data, guarantee of voluntary participation in this research, and publication of the results. The data were stored in a locked place in the researchers' institution. Written informed consent was obtained from all participants.

\section{Results}

A total of 22 older adults participated in the intervention program. Two participants who used long-term care services dropped out due to poor physical condition. Two of the participants refused quantitative assessments, and two others were absent from the postintervention assessments. Therefore, the results of 16 participants were valid for quantitative data analysis and 20 for qualitative data analysis. The details of the study participants are summarized in Tables 1 and 2.

[Insert Table 2 Here] 


\section{Results of quantitative data}

Descriptive statistics at baseline are shown in Table 2. Of the 16 participants for whom quantitative data were valid, nine had MCI, with an MMSE score of 27 or less at baseline.

Tables 3 and 4 show the results of comparison before and after the intervention for each measurement item. Significant improvements were observed in the MMSE-J $(t$ $=-2.99, p=.009, r=.61)$ and the physical $(t=-2.64, p=.025, r=.56)$ and psychological $(t=-3.42, p=.004, r=.72)$ domains of the WHOQOL-BREF, indicating a large effect size, respectively. The TMT-A $(t=2.05, p=.058, r=.47)$ and unrelated paired words of the S-PA $(t=-2.06, p=.057, r=.47)$ were not significant, but presented medium effect sizes and tended to improve. The total FAI-J score $(Z=-2.18$, $p=.029, r=.55)$ significantly decreased, indicating a large effect size. In terms of the items of the FAI-J, heavy housework $(Z=-1.81, p=.071, r=.45)$ did not show a significant difference, but did show a medium effect size and tended to increase. Gardening $(Z=-2.56, p=.011, r=.64)$ decreased significantly and showed a large effect size. There were no significant differences in local shopping $(Z=-1.414, p$ $=.157, r=-.35)$, actively pursuing a hobby $(Z=-1.582, p=.114, r=-.40)$, and gainful work $(Z=-1.633, p=.102, r=-.41)$, but they presented medium effect sizes and tended to decrease. Although there was no significant difference in GDS-15 J score $(Z=-$ $1.552, p=.121, r=.39)$, it showed a medium effect size and tended to improve. For the SOPI, there were no significant differences in the subcategories of productive activity $(Z=-1.484, p=.138, r=.37)$ and self-care $(Z=-1.688, p=.091, r=.42)$, but a declining trend was observed in the medium effect sizes. There were no significant differences in the TTM results.

[Insert Table 3 and Table 4 Here] 


\section{Results of qualitative data}

The participants' experiences in the Colour Narrative process were represented in the six categories described below. 'Negotiating occupations' was the core category. Additional examples of participants' interview excerpts are provided in Supplemental File 2, alongside their pseudonyms [Insert Supplemental File 2 Here]

\section{Core category: 'negotiating occupations'}

Participants talked about the harsh living conditions caused by heavy snowfall, including how snow shovelling was a heavy task that prevented them from doing other occupations. Participants had to negotiate occupations according to their available resources themselves. Participants acknowledged that their energy was limited. For the participants whose lives were negatively impacted by snow, the occupations they had engaged in before the winter sometimes became too much during the winter. However, some participants were able to use willpower to motivate themselves. Moreover, some participants were able to engage in valuable occupations by comparing the priority of their occupations, or changing the occupational forms by, for example, breaking the occupations down into smaller, more manageable parts.

The participants identified valuable occupations through the Colour Narrative program before the winter, in order to gain control in their lives. Some participants could only perform the occupations that were necessary for their daily lives. Others were able to engage in the occupations they wanted or were expected to do. Participants struggled to figure out how to engage in their valuable occupations with their limited resources and environment, with some participants succeeding and others never starting or giving up halfway through. Regardless of successes or shortcomings, the core of the 
participants' experiences was negotiating occupations.

\section{'Having one's life invaded by snow'}

For those who lived in the area with heavy snow, the impact of snow on daily lives was immense. In their area, snowfall occurs for nearly five months. While the number of outdoor occupations, such as hobbies, shopping, and gardening, became greatly limited in winter, the participants found it necessary to engage in the occupation of shovelling snow.

Fujita experienced depressing days where she felt oppressed by the snow, saying: 'This snow is killing me.' Another participant, Shimizu, explained that she would open the curtains to know whether it would snow the next day. The daily schedule was altered by whether or not snow shovelling was necessary, thus burdening the participants. In contrast, Okamoto, who actively engaged in various occupations throughout the year, explained that she was able to find more time throughout the day because snow restricted going out and related occupations.

\section{'Negotiating energy'}

Whether snow restricted other occupations in participants' lives depended on their energy management capabilities. Energy management was identified as one of the most important skills for negotiating occupations.

Ogawa found a parenting circle to be one of the most valuable occupations; however, she set cleaning as a goal. She had always felt guilty about prioritizing her favourite occupation over cleaning. She struggled to balance this important occupation with other occupations, and she explained her awareness of her limitations. Upon realizing how much time and effort she could dedicate to her occupations overall, Ogawa allocated time for cleaning accordingly. This could be considered as not only 
'negotiating energy' but also 'negotiating occupations themselves,' which is explained in the next category. Upon changing the occupational form according to what she could manage, she reached her goal of cleaning.

\section{'Negotiating occupations themselves'}

Participants were required to manage changes in occupational priorities. For example, some participants experienced unavoidable urgent occupations due to heavy snow or their spouses' poor health. Ikeda, who could not accomplish her target occupation at all, talked about how she was busy caring for her husband day and night, because his condition had worsened. She reflected about that time and said, 'Before the new year, really, I wasted whole days doing nothing'.

In order to achieve the targeted occupations, actively modifying occupations and taking charge of them was key. Sakamoto, for example, had a goal of practicing in a karaoke box alone, so that she could sing karaoke with her friends at parties. After thinking about what she should prioritize about karaoke, she realized that it was more important to be able to enjoy singing than to sing well. This enabled her to practice karaoke alone and perform at a New Year's party.

Being able to modify occupational forms was important for achieving targets for participants who set occupations requiring the presence of others ('being affected by connected things', which is described later). Maruyama, who originally loved sports, wanted 12 players to play volleyball as a winter sport. 'I invited some. But I couldn't get together enough players', Maruyama said sadly. Although other participants suggested different options to help him play, Maruyama insisted on not revising the original occupational form, saying that the type of volleyball that he knew had to be played with 12 players, and that he could not join sports events that he had never taken part in before. 


\section{'Negotiating willpower'}

Sakamoto explained why she took on solo karaoke as challenge that she wanted to try: 'If you don't act on your own, no one will take you. So, I have to do it by myself'. This statement demonstrates her strong willpower. Sakamoto set a goal of performing karaoke alone, which was not only an occupation of interest but also a self-determined goal that matched her values and current life. Her willpower strongly motivated her to carry out the actual occupational performance because it was a suitable occupation she had selected for herself.

Similar to Sakamoto, Harada expressed being motivated by strong willpower to engage in her occupations. Harada had to go out to perform her important occupations. She set meal planning and preparation as her goal. She was able to play the role of a traditional homemaker to her husband, and go out without worrying about him by planning and preparing meals. She had osteoarthritis in her knee, but she ignored her discomfort to go out for her important occupations.

\section{'Being affected by connected things'}

Some participants talked about the experience of being encouraged in their occupations by the presence of occupational partners. Nakano's goal was to increase the frequency of playing mah-jong by once or twice more per month. She did so by ensuring that her friends invited her as often as possible.

In contrast, in some cases, important things greatly influenced participants' motivation. Tamura's goal was 'to decide where to clean up today and do it bit by bit every day'. However, she said that the most important object, the stove, was broken, and that she was not motivated to clean the room in which it was placed. The people and things associated with participants' occupations had strong positive and/or negative 
effects on the motivation for the occupations and affected participants' 'negotiating willpower'.

\section{'Developing the targeted occupations'}

Some participants targeted other occupations that were related to their most valuable occupations. They described the experiences of not only accomplishing their target occupations but also the related occupations that were their valuable and ultimate goals. Some participants talked about experiences that were not intended at the time of goal setting, but had spilled over to other occupations because of performing the targeted occupations. Yamazaki, who had completed her goal of cleaning up the house, said that she had succeeded in making osechi, which are Japanese traditional New Year's dishes. For Yamazaki, both year-end cleaning and cooking osechi were essential and valuable occupations for welcoming the New Year.

\section{Integration of quantitative and qualitative results}

Based on the recommendations of Creswell [17], a side-by-side joint display is shown in Supplemental File 3. We examined the similarities and differences between the qualitative and quantitative results to analyze whether they converged or contrasted. Ultimately, both the quantitative and qualitative results largely supported and refined each other. One exception was related to GDS-15-J scores, which showed an improvement in the quantitative results; however, in the interviews, some participants expressed feeling depressed due to 'having one's life invaded by snow'. [Insert Supplemental File 3 Here]

\section{Discussion}

In the present study, the quantitative results showed a trend toward improvement in 
depressive symptoms and a significant improvement in HRQOL. Occupation-based preventive therapy programs have been reported to improve clients' HRQOL $[9,10,13,14]$. In this study, participants used ST to identify occupations they could engage in to improve their lives. Moreover, in the SM phase, although some participants did not succeed in meeting their occupational goals, all participants tried to conduct or review the valuable occupations they set as goals. This component of Colour Narrative may have helped to improve participants' depressive symptoms and HRQOL. Moreover, some participants experienced 'developing the targeted occupations'. This was an experience that evolved from the target occupations to other valuable occupations, and may have further improved participants' HRQOL.

Participants' MMSE scores showed significant improvement, while the S-PA and TMT-A showed improving trends. In particular, Colour Narrative may have been beneficial for participants' executive function. Executive function is an essential cognitive function for performing goal-oriented activities and is closely linked to the performance of and engagement in complex occupations [38]. Through ST, participants identified the occupations they wanted and/or needed to perform and chose the occupations for their goals. In the SM phase, as the qualitative data indicated in 'negotiating occupations', participants planned and carried out their goal occupations, as influenced by 'having one's life invaded by snow'. In the Well Elderly Study, participants' cognitive function was not affected [10]; however, Yokoi, Fujii, and Sakai [12] reported that participation in goal-oriented activities improved participants' cognitive function. These results suggest that goal-oriented components of the program may improve participants' cognitive function by activating participants' executive function. 
Furthermore, occupational ST itself may have a protective effect on cognitive function. Chippendale and Boltz [39] conducted a workshop on writing life stories for older adults and found significantly higher scores for meaning in life in the experimental group. Individuals with a high life purpose score have been reported to have a lower risk of developing dementia, a lower risk of cognitive decline [40], and better cognitive function than controls with similar levels of Alzheimer's disease [41]. The colour-based occupational ST and reflective occupational SM performed in groups in this study might have had a favourable effect on the participants' cognitive function; however, the mechanisms by which cognitive function is improved require further investigations.

Quantitative results showed a significant decline in overall activity and a declining trend in productivity and self-care on the SOPI. These were in line with the qualitative finding of 'having one's life invaded by snow', as both showed that the severe environmental condition of heavy snowfall restricted various activities for participants. Juvani, Isola, and Kyngäs [42] identified seasonal variation, temperature, snow, light variation, and distances as the main threats in the physical environment affecting the well-being of older adults in northern Finland. The current study was conducted in the northern area of Japan's subarctic zone, which has a similar physical environment to northern Finland. Hasegawa, Suzuki, and Yamauchi [43] investigated the physical activity levels and muscle strength of older adults in northern Japan. The results revealed that older adults' average number of steps was significantly lower in the snowy season. The significant reduction in overall activity during the winter in the current study is consistent with those results.

However, heavy housework on the FAI-J tended to increase. In the interviews, the participants repeatedly talked about the difficulties of shovelling snow, suggesting 
that it comprised most of their heavy housework. Participants' time and energy were greatly consumed by the heavy, and at times unpredictable, work of shovelling snow, as revealed by the theme of 'having one's life invaded by snow'. In contrast, as 'negotiating energy' revealed, participants who were good at energy management talked about and targeted occupations involving going out despite the snow. Moreover, characteristically, many participants set indoor occupations, such as cleaning, as their goals because of the difficulty of going out. Regardless of their situation, participants were required to reorganize their occupations according to the season, which led to the experience of 'negotiating occupations'.

Finally, while qualitative results showed that some participants felt depressed, as indicated in 'having one's life invaded by snow', the results of the GDS-15-J contrastingly showed rather significant improvement trends. The individual narratives and experiences may have influenced the qualitative data, while the collective treatment of participants may have influenced the quantitative data. Moreover, qualitative data helped understand the variations in participants' experiences. The strength of applying the mixed approach to evaluate the complex phenomena of participants' experiences was demonstrated.

\section{Methodological considerations/limitations}

We acknowledge there are limitations in this study. First, the small sample size of this study may affect the generalizability of the results. However, this sample size allowed us to collect both quantitative and qualitative data simultaneously from participants, which is a strength. The important results pertaining to significant improvement in participants' cognitive function through Colour Narrative can be attributed to the core of the participants' experience, namely, 'negotiating occupations'. The qualitative data showed that this negotiation could stimulate participants' cognitive function, even if 
they failed to achieve their occupational goals. These results do not appear when either quantitative or qualitative data are used alone. Such an advanced mixed methods approach combined the strengths of each design to compensate for the weaknesses, thereby increasing the validity and reliability of the study [17].

Second, heavy snowfall showed a large effect in this study. Qualitative data revealed that 'negotiating occupations' occurred not only in the Colour Narrative program but also in response to the need to manage heavy snow. Providing this intervention during the snowy season is of great practical significance; however, it is considered necessary to conduct a controlled study or an intervention study in a nonsnowy period to examine the effects of Colour Narrative without the effects of snow in participants' current lives.

Third, there were variations in the level of participants' cognitive function at baseline. Participants' MMSE scores ranged from 20-30 points. The effectiveness of the Colour Narrative program is expected to be limited if memory impairment is significant; however, this was not able to be verified in the present study because of the small sample size. Further research is needed to determine whether this intervention has differing effects according to levels of cognitive function.

\section{Conclusion}

This is the first study to investigate the adaptation of the occupational ST/SM approach to community-dwelling older adults. The aging of the world's population requires people to design their lives for an duration unprecedented in human history. Preventive occupational therapy shows promise for addressing this issue, and Colour Narrative offers a new occupation-based intervention strategy to occupational therapists working in this area. Further, the program's effectiveness should be further verified with an experimental design that incorporates a control group. 


\section{Acknowledgments}

This research was carried out with the aid of Hokkaido University COI 'Innovative Food \& Healthcare MASTER' and JSPS Research Fund (19K1986209). We appreciate Mr.Wataru Nagai, Mr. Takeshi Aoyama, and Mr. Hisashi Enomoto of A City Hall for assisting with the research field. In addition, we thank Mr. Joao Carlos Koch Junior of Sapporo Gakuin University, Hokkaido, Japan for content editing and proofreading this manuscript.

\section{Declaration of Conflicting Interests}

The authors declared no potential conflicts of interest with respect to the research, authorship, and/or publication of this article.

\section{Funding}

This research was carried out with the aid of Hokkaido University COI 'Innovative

Food \& Healthcare MASTER' [JPMJCE1301] and JSPS Research Fund [19K1986209].

\section{References}

1. Clark F. Occupation embedded in a real life: interweaving occupational science and occupational therapy. 1993 Eleanor Clarke Slagle Lecture. Am Occup Ther Assoc. 1993;47:1067-1078.

2. Zemke R, Ennevor BL, Richardson PL. A grounded theory of techniques for occupational storytelling and story making. In: Zemke R, Clark F, editors. Occupational science: the evolving discipline. Philadelphia, Pennsylvania: The F. A. Davis Company, 1996, p. 370-392.

3. Wright-St Clair V. Storymaking and storytelling: making sense of living with multiple sclerosis. J Occup Sci. 2003;10:46-51.

4. Gunnarsson AB, Peterson K, Leufstadius C, et al. Client perceptions of the Tree Theme Method ${ }^{\mathrm{TM}}$ : a structured intervention based on storytelling and creative activities. Scand J Occup Ther. 2009;17:1-9. 
5. Gunnarsson AB, Björklund A. Sustainable enhancement in clients who perceive the Tree Theme Method ${ }^{\circledR}$ as a positive intervention in psychosocial occupational therapy. Aust Occup Ther J. 2013;60:154-160.

6. Definitions of occupational therapy from member organisations [Internet]. World Federation of Occupational Therapy; [updated May 2018; cited 15 April 2020]. Available from: https://www.wfot.org/resources/definitions-of-occupationaltherapy-from-member-organisations

7. Definition of occupational therapy [Internet]. Japanese Association of Occupational Therapists; [updated 2018; cited 15 April 2020]. Available from: http://www.jaot.or.jp/en/index.html.

8. World population prospects 2019 highlights [Internet]. United Nations, Department of Economic and Social Affairs; [updated 2019; cited 15 April 2020]. Available from: https://population.un.org/wpp/Publications/Files/WPP2019_Highlights.pdf

9. Clark F, Azen SP, Zemke R, et al. Occupational therapy for independent-living older adults: a randomized controlled trial. J Am Med Assoc. 1997;278:1321-1326.

10. Clark F, Jackson J, Carlson M, et al. Effectiveness of a lifestyle intervention in promoting the well-being of independently living older people: results of the Well Elderly 2 Randomised Controlled Trial. J Epidemiol Community Health. 2012;66:782-790.

11. Clark F, Azen SP, Carlson M, et al. Embedding health-promoting changes into the daily lives of independent-living older adults: long-term follow-up of occupational therapy intervention. J Gerontol B Psychol Sci Soc Sci. 2001;56:60-63.

12. Yokoi K, Fujii Y, Sakai H. Ninchisyouyobouzigyou niokeru chyousensitaisagyouni shyotenwoateta apurouchino kouka. [Effectiveness of an approach focused on occupations that participants in a dementia prevention program want to try]. Sagyokagaku Zasshi. 2017;11:39-50. Japanese.

13. Kawamata H, Yamada T, Kobayashi N. [Effectiveness of an occupational therapy program for health promotion among healthy elderly. A randomized controlled trial]. Nihon Koshu Eisei Zasshi. 2012;59:73-81. Japanese.

14. Mountain G, Windle G, Hind D, et al. A preventative lifestyle intervention for older adults (lifestyle matters): a randomised controlled trial. Age Ageing. 2017;46:627-634. 
15. Boivin L. Image-based storytelling: a visual narrative of my family's story. CMAJ. 2018;190:E1112-E1113.

16. Drew SE, Duncan RE, Sawyer SM. Visual storytelling: a beneficial but challenging method for health research with young people. Qual Health Res. 2010;20:16771688.

17. Creswell JW. A concise introduction to mixed methods research. London: SAGE Publications, Inc., 2015.

18. Hikichi H, Kondo K, Takeda T, et al. Social interaction and cognitive decline: results of a 7-year community intervention. Alzheimers Dement (N Y). 2017;3:23-32.

19. Orimo K, Miura Namiko. Shinryojyo niokeru houkatsukea: Rokenni nyusyosuru ninchisyoriyousyaheno irokarutano kokorominitsuite. [Comprehensive care in a clinic: Color Karuta for the users with dementia in a long-term care facility]. Gekkan Chiikiigaku. 2010;24:114-116. Japanese.

20. International Classification of Functioning, Disability and Health (ICF). [Internet]. World Health Organization; [2001; cited 23 April 2020]. Available from: https://www.who.int/classifications/icf/en/.

21. Mitrushina M, Boone KB, Razani J, et al. Handbook of normative data for neuropsychological assessment. New York (NY): Oxford University Press, 1999.

22. Llinàs-Reglà J, Vilalta-Franch J, López-Pousa $\mathrm{S}$, et al. The Trail Making Test: association with other neuropsychological measures and normative values for adults aged 55 years and older from a Spanish-speaking population-based sample assessment. 2017;24:183-196.

23. Japan Society for Higher Brain Dysfunction BFTC. Hyojyun gengosei tsuirengougakusyuu kensa. [Standard verbal paired-associate learning test]. Tokyo: Shinkoh Igaku Shuppansha, 2014. Japanese.

24. Morihiro S, Yousuke K, Shinji S, et al. MMSE-J (seishinzyoutai tanzikankensanihonban) genpouno datouseitosinraisei. [The validity and reliability of the Japanese Version of the Mini-Mental State Examination (MMSE-J) with the original procedure of the Attention and Calculation Task (2001)]. Ninchisinkei Kagaku. 2018;20:91-110. Japanese.

25. Vertesi A, Lever JA, Molloy DW, et al. Standardized Mini-Mental State Examination. Use and interpretation. Can Fam Physician. 2001;47:2018-2023. 
26. Sugishita K, Sugishita M, Hemmi I, et al. A validity and reliability study of the Japanese version of the Geriatric Depression Scale 15 (GDS-15-J). Clin Gerontol. 2017;40:233-240.

27. Mitchell AJ, Bird V, Rizzo M, et al. Diagnostic validity and added value of the geriatric depression scale for depression in primary care: a meta-analysis of GDS30 and GDS15. J Affect Disord. 2010;125:10-17.

28. Marcus BH, Selby VC, Niaura RS, et al. Self-efficacy and the stages of exercise behavior change. Res Q Exerc Sport. 1992;63:60-66.

29. Pirzadeh A, Mostafavi F, Ghofranipour F, et al. Applying transtheoretical model to promote physical activities among women. Iran J Psychiatry Behav Sci. 2015;9:e1580.

30. Skevington SM, Lotfy M, O'Connell KA. The World Health Organization's WHOQOL-BREF quality of life assessment: psychometric properties and results of the international field trial. a report from the WHOQOL Group. Qual Life Res. 2004;13:299-310.

31. Holbrook, M. An activities index for use with stroke patients. Age Ageing. 1983; $12: 166-170$.

32. Han CW, Yajima Y, Nakajima K, et al. Construct validity of the Frenchay Activities Index for community-dwelling elderly in Japan. Tohoku J Exp Med. 2006;210:99-107.

33. Imai T, Saito S. Kozinnitotte kachinoarukatsudouno sankazyokyouno sokutei: zikisiki sagyousuikousihyouno kaihatsu. [Measuring the quality of participation in activities in everyday life: developing the Self-completed Occupational Performance Index ]. Sagyouryouhou. 2010; 29: 317-325. Japanese.

34. Field A. Discovering statistics using SPSS, 2nd ed. London: Sage Publications, Inc; 2005

35. Corbin JM, Strauss AL. Basics of qualitative research: techniques and procedures for developing grounded theory, fourth ed. SAGE Publications, Inc; 2015.

36. Lincoln YS, Guba EG. Naturalistic inquiry. Sage Publications; 1985.

37. Guba EG, Lincoln YS. Fourth generation evaluation. Sage Publications; 1989

38. Cramm H, Krupa T, Missiuna C, et al. The expanding relevance of executive functioning in occupational therapy: is it on your radar? Aust Occup Ther J. 2016;63:214-217. 
39. Chippendale T, Boltz M. Living Legends: Effectiveness of a program to enhance sense of purpose and meaning in life among community-dwelling older adults. Am J Occup Ther. 2015;69:1-11.

40. Boyle PA, Buchman AS, Barnes LL, et al. Effect of a purpose in life on risk of incident Alzheimer disease and mild cognitive impairment in communitydwelling older persons. Arch Gen Psychiatry. 2010;67:304-310.

41. Boyle PA, Buchman AS, Wilson RS, et al. Effect of purpose in life on the relation between Alzheimer disease pathologic changes on cognitive function in advanced age. Arch Gen Psychiatry. 2012;69:499-505.

42. Juvani S, Isola A, Kyngäs H. The northern physical environment and the well-being of the elderly aged over 65 years. Int J Circumpolar Health. 2005;64:246-256.

43. Hasegawa J, Suzuki H, Yamauchi T. Impact of season on the association between muscle strength/volume and physical activity among community-dwelling elderly people living in snowy-cold regions. J Physiol Anthropol. 2018;37:25. 
Table 1. Participants' occupational goals and whether they were performed and achieved $(\mathrm{n}=20)$

\begin{tabular}{|c|c|c|c|c|c|c|}
\hline Pseudonym & Age & Gender & Occupational goals & Feature of occupations & $\begin{array}{l}\text { Were occupations } \\
\text { performed? }\end{array}$ & $\begin{array}{l}\text { How well were the } \\
\text { goals achieved }\end{array}$ \\
\hline Shimizu & 76 & $\mathrm{~W}^{\mathrm{a}}$ & $\begin{array}{l}\text { To continue daily cooking and praying at } \\
\text { household altar }\end{array}$ & $\begin{array}{l}\text { Occupations that they } \\
\text { want to continue }\end{array}$ & Yes & Fully \\
\hline Yamazaki & 84 & $\mathrm{~W}$ & To do year-end housecleaning & $\begin{array}{l}\text { Occupations that they } \\
\text { want to continue }\end{array}$ & Yes & $\begin{array}{l}\text { Fully, beyond } \\
\text { expectations }\end{array}$ \\
\hline Mori & 85 & $\mathrm{~W}$ & To chat with friends twice a week & $\begin{array}{l}\text { Occupations that they } \\
\text { want to improve }\end{array}$ & Yes & Fully \\
\hline Abe & 76 & $\mathrm{~W}$ & $\begin{array}{l}\text { To make meals that her husband who had a } \\
\text { taste disorder could eat }\end{array}$ & $\begin{array}{l}\text { Occupations that they } \\
\text { want to improve }\end{array}$ & Yes & Not achieved \\
\hline Ikeda & 72 & $\mathrm{~W}$ & To clean more frequently & $\begin{array}{l}\text { Occupations that they } \\
\text { want to improve }\end{array}$ & No & Not achieved \\
\hline Yamashita & 74 & $\mathrm{~W}$ & To clean quickly & $\begin{array}{l}\text { Occupations that they } \\
\text { want to improve }\end{array}$ & No & Not achieved \\
\hline Maruyama & 82 & $\mathrm{M}^{\mathrm{b}}$ & To gather 12 players and play volleyball & $\begin{array}{l}\text { Occupations that they } \\
\text { want to restart }\end{array}$ & Mostly, yes & Not achieved \\
\hline Fujita & 70 & $\mathrm{~W}$ & $\begin{array}{l}\text { To make knitwear and other accessories } \\
\text { once or twice a month }\end{array}$ & $\begin{array}{l}\text { Occupations that they } \\
\text { want to take on as new } \\
\text { challenges }\end{array}$ & Mostly, yes & Not achieved \\
\hline
\end{tabular}




\begin{tabular}{|c|c|c|c|c|c|c|}
\hline Ogawa & 58 & $\mathrm{~W}$ & To clean once a week & $\begin{array}{l}\text { Occupations that they } \\
\text { want to improve }\end{array}$ & Yes & Partly \\
\hline Okada & 72 & $\mathrm{~W}$ & To knit almost every day in her spare time & $\begin{array}{l}\text { Occupations that they } \\
\text { want to continue }\end{array}$ & Yes & Fully \\
\hline Murakami & 70 & $\mathrm{~W}$ & $\begin{array}{l}\text { To cook balanced meals for staying healthy } \\
\text { To practice karaoke by listening to cassette } \\
\text { tapes at home }\end{array}$ & $\begin{array}{l}\text { Occupations that they } \\
\text { want to improve }\end{array}$ & Mostly, yes & Partly \\
\hline Sakamoto & 74 & $\mathrm{~W}$ & $\begin{array}{l}\text { To go to a karaoke room alone } \\
\text { To borrow books from a library once a } \\
\text { month }\end{array}$ & $\begin{array}{l}\text { Occupations that they } \\
\text { want to take on as new } \\
\text { challenges }\end{array}$ & Yes & $\begin{array}{l}\text { Fully, beyond } \\
\text { expectations }\end{array}$ \\
\hline Fukuda & 75 & $\mathrm{M}$ & $\begin{array}{l}\text { To think about how to keep electricity for a } \\
\text { long time in case of a blackout }\end{array}$ & $\begin{array}{l}\text { Not an occupational } \\
\text { goal }\end{array}$ & Yes & Fully \\
\hline Miura & 77 & $\mathrm{~W}$ & To learn how to knit sock covers & $\begin{array}{l}\text { Occupations that they } \\
\text { want to take on as new } \\
\text { challenges }\end{array}$ & Mostly, yes & Not achieved \\
\hline Okamoto & 73 & $\mathrm{~W}$ & $\begin{array}{l}\text { To organize documents according to items } \\
\text { as soon as they are received } \\
\text { To clean every day } \\
\text { To read books more than one hour a day } \\
\text { To practice playing the Japanese harp every } \\
\text { day }\end{array}$ & $\begin{array}{l}\text { Occupations that they } \\
\text { want to improve }\end{array}$ & Yes & Partly \\
\hline Matsuda & 78 & $\mathrm{~W}$ & $\begin{array}{l}\text { To offer water to the household altar every } \\
\text { day }\end{array}$ & $\begin{array}{l}\text { Occupations that they } \\
\text { want to continue }\end{array}$ & Yes & Fully \\
\hline
\end{tabular}




\begin{tabular}{|c|c|c|c|c|c|c|}
\hline Nakano & 76 & $\mathrm{~W}$ & $\begin{array}{l}\text { To increase the frequency of mah-jong by } \\
\text { once or twice a month }\end{array}$ & $\begin{array}{l}\text { Occupations that they } \\
\text { want to improve }\end{array}$ & Yes & Fully \\
\hline Harada & 77 & $\mathrm{~W}$ & $\begin{array}{l}\text { To plan and prepare meals for going out } \\
\text { with friends }\end{array}$ & $\begin{array}{l}\text { Occupations that they } \\
\text { want to take on as new } \\
\text { challenges }\end{array}$ & Yes & $\begin{array}{l}\text { Fully, beyond } \\
\text { expectations }\end{array}$ \\
\hline Tamura & 83 & $\mathrm{~W}$ & $\begin{array}{l}\text { To decide what to do today every day and } \\
\text { tidy up the house bit by bit }\end{array}$ & $\begin{array}{l}\text { Occupations that they } \\
\text { want to improve }\end{array}$ & No & Not achieved \\
\hline Takeuchi & 76 & $\mathrm{~W}$ & $\begin{array}{l}\text { To make flavourful pickles } \\
\text { To water the flowers every day }\end{array}$ & $\begin{array}{l}\text { Occupations that they } \\
\text { want to continue }\end{array}$ & Yes & Fully \\
\hline
\end{tabular}


Table 2. Demographics, mental function, activity, health-related quality of life, and participation in valuable occupations at baseline $(n=16)$

\begin{tabular}{|c|c|}
\hline \multicolumn{2}{|l|}{ Demographics } \\
\hline Average Age (years) & $74.9 \pm 6.1$ \\
\hline Gender (n (\%)) Man $/$ Woman & $2(12.5) / 14(87.5)$ \\
\hline Family structure (n (\%)) single-living/living together & $5(31.3) / 11(68.7)$ \\
\hline \multicolumn{2}{|l|}{ Mental function } \\
\hline MMSE-J (mean value) & $26.5 \pm 2.6$ \\
\hline \multicolumn{2}{|l|}{ MMSE-J (n) } \\
\hline 23 points or less & 1 \\
\hline $24-27$ points & 8 \\
\hline 28 or more points & 7 \\
\hline GDS-15-J (mean value) & $3.6 \pm 2.0$ \\
\hline \multicolumn{2}{|l|}{ Activity } \\
\hline \multicolumn{2}{|l|}{ TTM(n) } \\
\hline Precontemplation & 1 \\
\hline Contemplation & 0 \\
\hline Preparation & 1 \\
\hline Action & 2 \\
\hline Maintenance & 12 \\
\hline \multicolumn{2}{|l|}{ Health-related quality of life } \\
\hline \multicolumn{2}{|l|}{ WHOQOL-BREF (scores) } \\
\hline Average score of the all items & $3.2 \pm 0.2$ \\
\hline Physical & $3.1 \pm 0.3$ \\
\hline Psychological & $3.1 \pm 0.3$ \\
\hline Social & $3.6 \pm 0.4$ \\
\hline Environmental & $3.2 \pm 0.4$ \\
\hline General & $3.1 \pm 0.6$ \\
\hline \multicolumn{2}{|l|}{ Participation in valuable occupations } \\
\hline \multicolumn{2}{|l|}{$\mathrm{SOPI}^{\mathrm{a}}$} \\
\hline Total score & $86.6 \pm 12.3$ \\
\hline Leisure activity & $94.3 \pm 8.7$ \\
\hline Productive activity & $82.3 \pm 17.4$ \\
\hline Self-care & $83.3 \pm 18.9$ \\
\hline
\end{tabular}

Note. TTM: Transtheoretical model; MMSE-J: Mini-Mental State Examination-Japanese; GDS-15-J: Geriatric Depression Scale-15-Japanese; WHOQOL-BREF: World Health Organization Quality of Life 26; SOPI: Self-completed Occupational Performance Index. ${ }^{a}$ Each score was converted to 100 points in the SOPI. 
Table 3. Comparison of baseline and endpoint assessments of cognitive function $(n=16)$

\begin{tabular}{lcccccccc}
\hline Variables & \multicolumn{2}{c}{ Baseline } & \multicolumn{2}{c}{ Endpoint } & $p$-value & Effect size- $r$ \\
\hline TMT-A (seconds) & 53.9 & \pm & 12.2 & 49.3 & \pm 11.6 & .058 & .47 \\
$\begin{array}{l}\text { S-PA } \\
\quad \text { Related paired words } \\
\text { (number of pairs) }\end{array}$ & 28.5 & \pm & 1.7 & 27.1 & \pm 4.7 & .333 & -.25 \\
$\begin{array}{l}\text { Unrelated paired } \\
\text { words (number of } \\
\text { pairs) }\end{array}$ & 5.1 & \pm & 6.5 & 8.1 & \pm 6.9 & .057 & .47 \\
$\begin{array}{l}\text { MMSE-J } \\
\text { MMSE }\end{array}$ & 26.5 & \pm 2.6 & 28.3 & \pm 1.4 & $.009 *$ & .61 \\
\hline
\end{tabular}

Note. Values are means \pm Standard deviation; ${ }^{*} p<.05$; Effect size $r$ : small $(r \geqq .10)$, medium ( $r \geqq .30$ ), large ( $r \geqq .50$ ). TMT-A: Trail Making Test-Part A; S-PA: Standard verbal paired-associate learning test; MMSE-J: Mini-Mental State Examination-Japanese. 
Table 4. Comparison of baseline and endpoint assessments of mental function, instrumental activity of daily living, exercise habits, participation in valuable occupations, and health-related quality of life $(\mathrm{n}=16)$

\begin{tabular}{|c|c|c|c|c|c|c|c|c|c|}
\hline \multirow[t]{2}{*}{ Variables } & \multicolumn{3}{|c|}{ Baseline } & \multicolumn{3}{|c|}{ Endpoint } & \multirow{2}{*}{\multicolumn{2}{|c|}{$p$-value }} & \multirow[b]{2}{*}{ Effect size- $r$} \\
\hline & $25 \%$ ile & Median & $75 \%$ ile & $25 \%$ ile & Median & $75 \%$ ile & & & \\
\hline GDS-15-J (scores) & 2.0 & 3.0 & 5.0 & 1.0 & 2.0 & 4.0 & .121 & & .39 \\
\hline \multicolumn{10}{|l|}{ FAI-J (scores) } \\
\hline $\begin{array}{l}\text { Total sore } \\
\text { Items with medium or large } \\
\text { effect size }^{\mathrm{a}}\end{array}$ & 31.0 & 32.5 & 35.0 & 28.0 & 31.0 & 33.8 & .029 & $*$ & -.55 \\
\hline Heavy housework & 2.0 & 3.0 & 3.0 & 3.0 & 3.0 & 3.0 & .071 & & .45 \\
\hline Local shopping & 3.0 & 3.0 & 3.0 & 3.0 & 3.0 & 3.0 & .157 & & -.35 \\
\hline Actively pursuing hobby & 3.0 & 3.0 & 3.0 & 0.5 & 3.0 & 3.0 & .114 & & -.40 \\
\hline Gardening & 1.0 & 3.0 & 3.0 & 0.3 & 1.0 & 1.8 & .011 & $*$ & -.64 \\
\hline Gainful work & 0.0 & 0.0 & 0.8 & 0.0 & 0.0 & 0.0 & .102 & & -.41 \\
\hline TTM & 4.3 & 5.0 & 5.0 & 2.3 & 5.0 & 5.0 & .269 & & -.28 \\
\hline \multicolumn{10}{|l|}{ SOPI (scores) } \\
\hline Total score & 77.8 & 88.9 & 97.2 & 86.1 & 90.3 & 94.4 & .292 & & .26 \\
\hline Leisure activity & 91.7 & 100.0 & 100.0 & 85.4 & 91.7 & 100.0 & .439 & & -.19 \\
\hline Productive activity & 68.8 & 87.5 & 97.9 & 83.3 & 91.7 & 91.7 & .138 & & -.37 \\
\hline Self-care & 66.7 & 91.7 & 100.0 & 83.3 & 91.7 & 100.0 & .091 & & -.42 \\
\hline \multicolumn{10}{|l|}{ WHOQOL-BREF (scores) } \\
\hline Physical & 2.8 & 3.0 & 3.3 & 3.0 & 3.1 & 3.5 & .025 & * & .56 \\
\hline Psychological & 2.8 & 3.0 & 3.3 & 3.0 & 3.2 & 3.5 & .004 & * & .72 \\
\hline Social & 3.3 & 3.7 & 3.7 & 3.4 & 3.7 & 3.9 & .065 & & .46 \\
\hline Environmental & 2.9 & 3.3 & 3.5 & 3.0 & 3.3 & 3.7 & .195 & & .32 \\
\hline General & 3.0 & 3.0 & 3.5 & 3.0 & 3.5 & 3.9 & .361 & & .23 \\
\hline
\end{tabular}

Note. \%ile : percentile; ${ }^{*} p<.05$; Effect size $r$ : small $(r \geqq .10)$, medium $(r \geqq .30)$, large $(r \geqq .50)$. TTM: Transtheoretical model; FAI- 
J: Frenchay Activities Index-Japanese; GDS-15-J: Geriatric Depression Scale-15-Japanese; WHOQOL-BREF: World Health Organization Quality of Life 26; SOPI: Self-completed Occupational Performance Index.

${ }^{a}$ Of the total 15 items, only those with moderate or large effect sizes were listed. 
Supplemental File 1. Participants' actual occupational performance in Phase 3 and their updated goals at Phase 4

\begin{tabular}{|c|c|c|}
\hline Pseudonym & Occupational performance in Phase 3 & Updated goals at Phase 4 \\
\hline Shimizu & $\begin{array}{l}\text { She consciously worked on her goals by } \\
\text { placing the paper with her goal on the } \\
\text { refrigerator. }\end{array}$ & $\begin{array}{l}\text { To live a healthy life from } \\
\text { now on }\end{array}$ \\
\hline Yamazaki & $\begin{array}{l}\text { She met her goal to show to her family her } \\
\text { pride in the fact that she could live in her } \\
\text { own house, who had recommended she live } \\
\text { in an institution. } \\
\text { Owing to the success of the housecleaning, } \\
\text { her preparation of New Year's dishes also } \\
\text { went well. }\end{array}$ & $\begin{array}{l}\text { To keep doing crossword } \\
\text { puzzles so that she could } \\
\text { engage in mental activity to } \\
\text { prevent dementia }\end{array}$ \\
\hline Mori & $\begin{array}{l}\text { Although she did not remember her goals, } \\
\text { the other members visited her home, } \\
\text { remembering her goals. }\end{array}$ & To walk every day \\
\hline Abe & $\begin{array}{l}\text { Despite her ingenuity, her husband's } \\
\text { responses were sometimes good and } \\
\text { sometimes bad. }\end{array}$ & $\begin{array}{l}\text { To use more ingenuity in } \\
\text { making meals that her } \\
\text { husband could eat }\end{array}$ \\
\hline Ikeda & $\begin{array}{l}\text { She was taking care of her husband, whose } \\
\text { condition worsened; therefore, she was } \\
\text { unable to do the cleaning. }\end{array}$ & $\begin{array}{l}\text { To exercise with her husband } \\
\text { for spring and be able to } \\
\text { attend gatherings }\end{array}$ \\
\hline Yamashita & She was worn out by snow shovelling. & To not fret \\
\hline
\end{tabular}

Maruyama He looked for players, but could not get 12. To try something else that's said to be good for health, because he could not play sports in the winter

Fujita She was worn out by snow shovelling. To change her mood and try lunch and movies with friends, and knitting for the rest of winter.

Ogawa She had always felt guilty for putting off To renovate her house a little cleaning. She was able to clean by dividing the space to the extent that she could manage.

Okada She knitted because she did not want her husband to see her inactively lying on the sofa, and also practiced how to knit to teach the other members

To do radio calisthenics almost every day 
Murakami Cooking was a daily activity, and she did it because she had to manage her diabetes. In contrast, karaoke was not performed, because it was less urgent.

Sakamoto She ventured to karaoke alone and found it To eat out alone easier than she thought.

She also performed karaoke at a New Year's party.

Fukuda His son brought him a battery.

Miura

Okamoto

Matsuda

Nakano

Harada

Tamura

Takeuchi
She could not do it because the person from whom she wanted to learn was continuously absent from the 'salon'. because she thought it was necessary to show respect to guests who would enter the house.

In contrast, other goals were less urgent, so they were put off.

Since not only her husband but also her son were in the household altar, she wanted to take good care of it; thus, she continued offering the altar water and meals every day.

Mah-jong requires four players and equipment. She tried not to miss an everything, though she did opportunity to be invited by a friend who had not really like going out. the equipment.

She did well because it was an essential task to ensure that she could go out without hesitation.

She wanted to tidy up the room for her important stove, but the stove broke suddenly, and she lost her motivation fully.

She did well because they were already habits.

To take an interest in

To exercise

To decide what to do every day and tidy up the house bit by bit

To monitor the growth of an orchid
She started vacuuming her house every day
To try to walk and move her body as much as possible

To knit socks in a unique way

To enjoy hobbies

To knit sock covers

To focus on one goal of keeping things tidy

To plant a pineapple

To complete the vest that she was knitting 
Supplemental File 2. Participants' interview excerpts

\begin{tabular}{|c|c|c|}
\hline Category & $\begin{array}{l}\text { Participant's } \\
\text { pseudonym }\end{array}$ & Raw narrative excerpts \\
\hline \multirow[t]{2}{*}{$\begin{array}{l}\text { 'Having one's life } \\
\text { invaded by snow' }\end{array}$} & Fujita & $\begin{array}{l}\text { 'I don't feel well. It must have snowed heavily in February, too. No matter what I do, } \\
\text { well, there are books piled up there, and even if I want to read one, after a few pages, ha, } \\
\text { I want to quit it. I have something I want to read, but this snow may have completely } \\
\text { destroyed me'. }\end{array}$ \\
\hline & Okamoto & $\begin{array}{l}\text { 'I noticed that it doesn't take so long (to vacuum a room). But I can't do it in summer, } \\
\text { because I often go to play park golf and so on. And the days are longer in summer. There } \\
\text { is snow now, but I think it can't be helped. So, I can vacuum a room'. }\end{array}$ \\
\hline \multirow[t]{2}{*}{ 'Negotiating energy' } & Ogawa & $\begin{array}{l}\text { 'When I'm starting to make stuff (for the parenting circle), you know, I start to think, like, } \\
\text { it's all right that I am prioritizing doing it during that time. Afterwards, I would think that } \\
\text { it would be nice to go back to my usual routine. I thought I couldn't do both, because I } \\
\text { thought it was impossible'. }\end{array}$ \\
\hline & Ogawa & $\begin{array}{l}\text { 'I thought I should divide the space to clean in half. I thought I could divide it in half or } \\
\text { one-fourths. When the time comes, my eyes begin to feel heavy, and time seems to fly, } \\
\text { and it becomes late at night. If I feel I can't do it anymore, I just leave it'. }\end{array}$ \\
\hline \multirow[t]{2}{*}{$\begin{array}{l}\text { 'Negotiating } \\
\text { occupations } \\
\text { themselves' }\end{array}$} & Sakamoto & $\begin{array}{l}\text { 'I know I'm terrible at singing. But my vocalizing is good, and I don't think that I need to } \\
\text { be good at it because I'm old. As long as I am having fun. I think it's all right as long as I } \\
\text { enjoy it, so I decided to sing'. }\end{array}$ \\
\hline & Yamazaki & $\begin{array}{l}\text { 'To clean the bottom of the sink, I always use cellophane tape or packing tape to fold the } \\
\text { mat underneath the sink. This year, you know, I can't bend my knees, because if I sit flat, } \\
\text { I can't stand up. It's clear. But I did. I measured the mat first and stapled it all the way.... I } \\
\text { have a thing, like a back-scratcher, to nip binds and trashcans and anything. I used it to } \\
\text { nip the mat and stapled it and cleaned there.' }\end{array}$ \\
\hline
\end{tabular}


'Negotiating

willpower'

Harada

Okada

'Being affected by connected things'

Nakano

'Developing the targeted occupations'

Tamura
I'm exercising and so on. My knees are strained because I'm this fat. I was busy and had to go out, especially in January. So, I don't want to think about my knees hurting because I have to go. You know, because I want to go'.

'I knitted almost every night.... I don't want to sit around in front of my husband, so I have to pretend to be doing something. I'm worrying about something strange.... I feel like I'm on autopilot before going to bed after my husband goes to bed. You know what? I'm showing off to my husband. It's bad that the two of us are in a daze, don't you think so? I care a lot [about my husband]. Don't you do that?'

'I wish I could play mah-jong by myself, but I can't play mah-jong without four players. So, if someone invites me, I say yes every time.... I was invited by a friend, and the number of times has increased by once or twice more a month, so my goal has mostly come true.'

'I had a stove that was almost 40 years old. There used to be a stove in the middle of the room in those days, you know. Now, it looks so fashionable, and people praised my stove, well, it's a rare and wonderful stove. It was like the queen of my room, and I liked her because she was very stylish. The stove was about 40 years old. I always took off the net and cleaned everything, and when the glass fogged, wiped the glass and did everything, but all of a sudden, it does not turn on anymore because it is old. I put the stove in the middle. It was really warm. Now, I can't tidy up any more. It's all over now.'

Yamazaki

'I did year-end cleaning, and it was perfect. Great. Yeah. Then, I cooked osechi at the end of the year to some extent. When I made simmered black beans (that is one osechi dish), I did it very well. And my husband said, "the simmered black beans are delicious, so cook them more," so I went to buy more beans'.

Sakamoto 'When you join a New Year's party of any group, you want to sing don't you? If it's a New Year's party of a group of people or some kind of meeting, everyone sings, so I don't want to be alone in that corner. That's why I tried [practicing karaoke by myself]. Then, I sang at this year's New Year's party.' 
Supplemental File 3. Comparison of quantitative and qualitative data

\begin{tabular}{|c|c|c|}
\hline $\begin{array}{l}\text { Results of quantitative } \\
\text { measurements for outcome } \\
\text { assessment }\end{array}$ & $\begin{array}{l}\text { Results of qualitative group } \\
\text { interviews for process } \\
\text { assessment }\end{array}$ & $\begin{array}{l}\text { milarities and differences between quantitative and qualitative } \\
\text { sults }\end{array}$ \\
\hline $\begin{array}{l}\text { Mental function } \\
\text { - }[\star] \text { There was no significant } \\
\text { difference in GDS-15-J, but } \\
\text { there was a moderate } \\
\text { improvement trend. } \\
\text { - [ }] \text { Cognitive function } \\
\text { significantly improved. } \\
\text { Activity } \\
\text { - [ } \mathbf{\Delta}] \text { As for IADL, the } \\
\text { frequency of gardening } \\
\text { decreased significantly. The } \\
\text { frequency of shopping, } \\
\text { hobbies, and work showed a } \\
\text { declining trend, while the } \\
\text { frequency of heavy } \\
\text { housework showed an } \\
\text { increasing trend. Overall } \\
\text { activity was significantly } \\
\text { reduced. } \\
\text { - [ } \mathbf{\Delta}] \text { There was no significant } \\
\text { difference in exercise habits. } \\
\text { Participation } \\
\text { - [ } \mathbf{\Delta}] \text { There was no significant } \\
\text { difference in SOPI, but } \\
\text { productivity and self-care } \\
\text { showed a declining trend. } \\
\text { HRQOL }\end{array}$ & $\begin{array}{l}\text { Core category: } \\
\text { [ ] Negotiating occupations } \\
\text { Participants described the harsh } \\
\text { living conditions due to heavy } \\
\text { snowfall and the limitations of } \\
\text { their energy. However, before } \\
\text { this winter, they had identified } \\
\text { occupations to improve their } \\
\text { winter lives and set the } \\
\text { occupations as their unique } \\
\text { goals through Colour Narrative. } \\
\text { Trying to accomplish their } \\
\text { targeted occupations on their } \\
\text { own was an attempt to control } \\
\text { and have ownership of their } \\
\text { lives that had been disrupted by } \\
\text { snow. } \\
\text { Regardless of whether their } \\
\text { targeted occupations were } \\
\text { achieved, the core of their } \\
\text { experience was the negotiation } \\
\text { of their occupations. } \\
\text { The subcategories were as } \\
\text { follows: } \\
\text { - [ } \mathbf{\Delta} \text { ] 'Having one's life } \\
\text { invaded by snow' } \\
\text { - } \$ \text { ] 'Negotiating energy' }\end{array}$ & $\begin{array}{l}\text { Convergence } \\
\text { - [ } \star \text { ] Participants' depressive symptoms tended to improve, and } \\
\text { HRQOL significantly improved. Some participants } \\
\text { experienced 'developing the targeted occupations'. These } \\
\text { results may complement each other. However, it was inferred } \\
\text { that not only the SM-phase but also the experience of talking } \\
\text { about one's own occupational story through ST and engaging } \\
\text { in the valuable occupations that were set as goals influenced } \\
\text { the improvement of depressive symptoms and HRQOL. } \\
\text { - } \bullet \text { ] The significant improvements in cognitive function may } \\
\text { be explained by 'negotiating occupations', which was the core } \\
\text { of participants' experiences through SM. Participants } \\
\text { experienced 'being affected by connected things' in both } \\
\text { positive and negative ways when 'negotiating energy', } \\
\text { 'negotiating occupations themselves', and 'negotiating } \\
\text { willpower'. These negotiations may have become intellectual } \\
\text { tasks for participants and activated their cognitive function. } \\
\text { [ } \mathbf{\Delta} \text { ] Quantitative results showed a significant decline of } \\
\text { overall activity and a declining trend in SOPI. These were } \\
\text { convergent with the qualitative result of 'having one's life } \\
\text { invaded by snow'. Both results showed that the severe living } \\
\text { environment caused by heavy snowfall restricted various } \\
\text { activities. However, snow shovelling as a form of heavy } \\
\text { housework increased, indicating that this increased activity } \\
\text { prevented participants from engaging in other occupations. } \\
\text { Contradiction } \\
\text { - [ } \star \mathbf{\Delta} \text { ] In 'having one's life invaded by snow', some }\end{array}$ \\
\hline
\end{tabular}


- $[\star]$ Significant improvements were seen in the physical and psychological domains of HRQOL.
- $[>$ 'Negotiating occupations themselves'

- $[\bullet]$ 'Negotiating willpower'

- $[\bullet]$ 'Being affected by connected things'

- $[\star]$ 'Developing the targeted occupations participants said in the interviews that they felt depressed because they were overwhelmed by heavy snow. This qualitative result contradicted the quantitative result of a tendency toward improvement in depressive symptoms.

Note. IADL: Instrumental activities of daily living; HRQOL: Health-related Quality of Life; GDS-15-J: Geriatric Depression Scale-15Japanese; SOPI: Self-completed Occupational Performance Index. The same symbol $[\star, \bullet, \boldsymbol{\Delta}]$ is presented at the beginning the corresponding items. 